\title{
Food web structure of three Mediterranean stream reaches along a gradient of anthropogenic impact
}

\author{
Katarzyna Sroczyńska • Tanner J. Williamson • Marilia Claro • \\ José A. González-Pérez $\cdot$ Pedro Range $\cdot$ Tomasz Boski $\cdot$ Luis Chícharo
}

Received: 13 June 2019/Revised: 9 April 2020/Accepted: 11 April 2020/Published online: 24 April 2020

(C) Springer Nature Switzerland AG 2020

\begin{abstract}
Anthropogenic impact can alter food web structure through changes in species interactions. In this study, we explored the food web of three Mediterranean stream reaches (two seasonal and one permanent) along an anthropogenic impact gradient to test the hypothesis that increasing impact simplifies food webs. To test this, we applied the isotopic $\left(\delta^{13} \mathrm{C}\right.$ and $\delta^{15} \mathrm{~N}$ ) niche concept to compare reaches using isotopic metrics (isotopic richness, divergence,
\end{abstract}

Handling editor: María del Mar Sánchez-Montoya

Electronic supplementary material The online version of this article (https://doi.org/10.1007/s10750-020-04263-5) contains supplementary material, which is available to authorized users.

K. Sroczyńska $(\bowtie) \cdot$ L. Chícharo

Faculty of Science and Technology, Campus of

Gambelas, University of Algarve, 8005-139 Faro,

Portugal

e-mail: kasiasroczynska@gmail.com

K. Sroczyńska

MARE-Marine and Environmental Sciences Centre, University of Évora, Apartado 94, 7002-554 Évora, Portugal

T. J. Williamson

Department of Biology, Miami University, Oxford, $\mathrm{OH}$, USA

M. Claro

Centre for Marine Sciences, University of Algarve, Campus de Gambelas, 8005-139 Faro, Portugal dispersion, evenness, and redundancy). The isotopic indices were useful to identify differences in food web architecture among the three reaches. The least impacted site had the highest isotopic richness, dispersion, and isotopic redundancy, suggesting higher ecological resilience at this site. The effect of disturbance in the remaining two sites was masked by the presence of invasive crayfish, which increased isotopic divergence and was responsible for higher food-chain length in the most impacted reach, but not in the moderately impacted reach. Consumers displayed generalistic feeding habits, with Bayesian mixing models indicating that they relied primarily on a mixture of periphyton, other macroinvertebrates, and to a lesser extent, detritus. Some taxa displayed

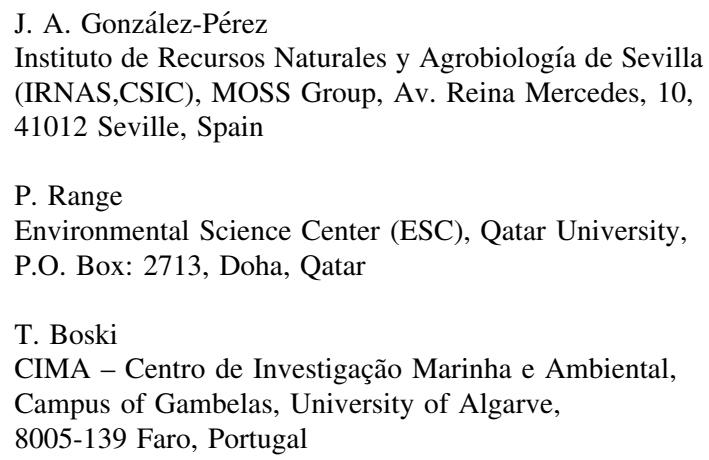


changes in their dietary habitats depending on the site, indicating that the same type of taxa fed on distinct foods at each stream reach.

Keywords Stable isotopes - Carbon · Nitrogen · Isotopic metrics $\cdot$ Macroinvertebrates

\section{Introduction}

Anthropogenic pressures are causing unprecedented changes to community structure, altering the strength of biotic interactions with direct negative effects on biodiversity and consequently on ecosystem functioning (Cardinale et al., 2012). A current challenge is to detect changes in altered ecosystems in order to adequately characterize their ecological status, and to eventually design conservation measures. Current biodiversity assessment techniques evaluate the pressure on a given group of species or entire communities, but they seldom consider the interactions among them. Ecological networks such as food webs incorporate interaction effects, providing a more complete link between community structure and function (Gray et al., 2014).

Food webs describe the structural organization of biota across trophic levels through their feeding links (Junker, 2008) and therefore account for trophic interactions among multiple trophic levels. Food webs are extremely dynamic in space and time as a consequence of environmental variation, species assemblages, and their adaptive capacities and ecological interactions (Pascual \& Dunne, 2006; SánchezCarmona et al., 2012; López-Rodríguez et al., 2012a; Vannucchi et al., 2013, 2017), and are thereby crucial in understanding the stability and persistence of a given ecosystem.

According to niche partitioning theory, higher competition for resources among even closely related species, should promote specialization and a wider spectrum of resource use, eventually increasing the number of traits and trophic niche size (McKane et al., 2002). Disturbance has been demonstrated to influence food web architecture by reducing the number of trophic groups and links, lowering maximum trophic level and reducing niche size (Layer et al., 2010; Coll et al., 2011; Gray et al., 2014; Thompson et al., 2012). For example, drought in streams can lead to a loss of sensitive large predators, thereby weakening food web energy fluxes (Ledger et al., 2013). In contrast, O'Gorman et al. (2012) demonstrated that increasing disturbance increased connectance and food chain length in coastal environments due to the presence of generalistic type predators. Different type of disturbances affect different trophic levels, but the overall effect can be only assessed from the network perspective, rather than simple species loss (Gray et al., 2014).

One of the most efficient tools to study trophic interactions are carbon and nitrogen stable isotopes analysis (SIA). Carbon isotope ratios (specifically the ${ }^{13} \mathrm{C} /{ }^{12} \mathrm{C}$ expressed as $\delta^{13} \mathrm{C} \%$ ) allow tracing of allochthonous (e.g., terrestrial litter) and autochthonous (e.g., algae) organic matter sources through aquatic food webs (Bunn et al., 1989; France, 1996a; France, 1996b; Rosenfeld \& Roff, 1992). Nitrogen ${ }^{15} \mathrm{~N} /{ }^{14} \mathrm{~N}$ stable isotope ratios expressed as $\delta^{15} \mathrm{~N} \%$ are extremely useful in identifying trophic relationships due to constant fractionation against the heavier isotope with increasing trophic level (Minagawa \& Wada, 1984; Zanden \& Rasmussen, 2001; Vanderklift \& Ponsard, 2003).

Combination of both isotopes is usually represented graphically with carbon vs nitrogen biplots that allow us to infer trophic position and diet of individual consumers. Factors that regulate carbon uptake by aquatic producers, such as water velocity, light, and temperature (Sackett et al., 1965; Osmond et al., 1981; Wienke \& Fischer, 1990; Finlay et al., 1999; Ishikawa et al., 2012) are rarely constant within a stream reach and their variation in turn affects algal $\delta^{13} \mathrm{C}$ and $\delta^{15} \mathrm{~N}$ values (Rosenfeld \& Roff, 1992). For this reason, single isotopic values of consumers and their resources can demonstrate large variability even at small spatial scale (Winterbourn et al., 1986; Hamilton \& Lewis, 1992; Rosenfeld \& Roff, 1992; France, 1995).

Increasing use of stable isotopes in food web ecology and the need for a comparable approach gave rise to the isotopic niche concept (Jackson et al., 2012; Layman et al., 2012), and the development of respective standardized isotopic metrics first proposed by Layman et al. (2007). Isotopic niche is defined as an isotopic space occupied by various components of a food web within a $\mathrm{C}-\mathrm{N}$ biplot. $\mathrm{C}$ and $\mathrm{N}$ values of each component are standardized relative to its community centroid to allow comparisons between sites. Isotopic metrics are calculated based on isotopic niches providing integrative (for temporal and spatial 
variability) and comparable (between sites or ecosystems) approaches for food web analysis. One aspect that was not included in Layman's metrics is organism traits, such as biomass or abundance. In response to this issue, Cucherousset and Villeger (2015) developed a metric complementary to Layman et al. (2007), where individual abundance or biomass is included in the metric's calculation. These metrics include: isotopic richness (corresponding to Layman's (2007) isotopic convex hull area), isotopic divergence, dispersion, evenness and uniqueness (Cucherousset \& Villeger, 2015). Except for isotopic richness, all presented metrics take species traits (biomass or abundance) into account, giving different significance to rare and common species (Layman et al., 2007; Jackson et al., 2011) and thereby providing more realistic insight into community structure.

Isotopic richness (Irich) is measured by the convex hull area, which is an amount of isotopic space filled by the groups of consumers, whereas isotopic divergence (Idiv) also accounts for the distribution and weights of consumers, within the convex hull. Isotopic dispersion (IDis) accounts for both: convex hull area and isotopic divergence and isotopic evenness (IEve) also accounts for the distance between the organisms, being high when all the organisms are regularly distributed in the isotopic space and close to 0 when some consumers are packed within a small area of the convex hull and few other are far from this group. Isotopic uniqueness (IUni) measures of how close consumers are in the stable isotopic space and it inversely corresponds to isotopic redundancy.

The majority of Mediterranean climate freshwater ecosystems (streams, ponds, lakes, and estuaries) have intermittent flow regimes, which are highly dependent on weather conditions. They periodically dry during the hottest months and start to flow again by the end of autumn when precipitation increases. Shifts in hydrological regime and reduction in the flowing period make them highly prone to recent climate changes and consequently, additional disturbances (i.e. increased nutrient input) to these already vulnerable ecosystems might seriously threaten ecological stability and promote irreversible degradation (Sabo et al., 2010; Stubbington et al., 2017, Mor et al., 2018). Mediterranean seasonal ecosystems have a vital role in maintaining biodiversity and providing essential ecosystem services (Acuña et al., 2017). Given the urgent need to protect these ecosystems, it is imperative that we develop better tools to capture and predict complex ecosystem response to anthropogenic pressures.

However, disturbance effects on the food web properties of Mediterranean temporary streams are relatively understudied (Mor et al., 2018). And information on food webs alone is mainly derived from functional feeding groups (FFGs) classification (Álvarez \& Pardo, 2009). Although they provide valuable insight into food web structure, it has been recognized that FFG classification does not reflect actual consumer diets (Lauridsen et al., 2014). Further, the majority of consumers can adapt to a wide variety of food resources, particularly in the environments with high variability of food resources and hydrodynamic conditions, such as seasonal streams (SánchezCarmona et al., 2012).

To address this knowledge gap, we investigated food web responses to varying degrees of human impact at three Mediterranean reaches using the above-mentioned isotopic metrics. Our three study sites mainly varied in their proportion of human land use, nutrient input from surrounding landscapes, and degree of invasion by the giant reed (Arundo donax L.). According to theory (Pearson \& Rosenberg, 1978) low resource heterogeneity and high primary productivity should reduce competition for basal resources, increasing the number of generalistic, more tolerant species, while reducing the number of specialized taxa. This would decrease the link between top and intermediate species, producing a simplified food web with shorter chain length and width.

Accordingly, our predictions assumed that increasing anthropogenic impact would produce a decline in isotopic richness, evenness, and dispersion, resulting in simpler food webs. We predicted this would translate to increased omnivory along the impact gradient. Therefore, individuals in the most impacted stream would be more omnivory-based than the same taxa at less impacted sites. To test these hypotheses, three study reaches were characterized using $\mathrm{C}$ and $\mathrm{N}$ stable isotopes and previously mentioned isotopic metrics. Additionally, we quantified the relative contribution of different food sources to a diet of consumers using Bayesian mixing models (Parnell \& Jackson, 2013). 


\section{Methods}

\section{Study sites}

Quarteira River Basin is located in Algarve region of southern Portugal (Fig. 1). The catchment area is $\sim 324 \mathrm{~km}^{2}$ and the elevation ranges from 14 to $515 \mathrm{~m}$. The average monthly air temperature varies from 8 to $29^{\circ} \mathrm{C}$ and average annual rainfall is $625 \mathrm{~mm}$. Catchment land use consists of olive tree plantations and other cultivated tree crops including almond, carob, cork oak, and citrus. Non-agricultural land cover includes shrub and herbaceous vegetation, and mixed forest. Along the site margins, depositional, low flow pools are filled with accumulated leaf litter from adjacent riparian vegetation underlain by clay. Channel substrate is predominantly gravel and cobble, which is densely covered by filamentous algae, mainly Cladophora agg. and Vaucheria $\mathrm{sp}(\mathrm{p}$.), during the summer season. Three sites, Monte Seco, Quinta da Ombria, and Fonte Benemola, were sampled (Fig. 1). Sampling points were selected from the monitoring grid defined by the Portuguese Water Institute I.P. (INAG) for the Algarve Water District (ARH Algarve). Site selection was based on Chícharo et al. (2009) who evaluated water quality at given sites taking into consideration river habitat following the mandatory Water Framework Directive (WFD, EU, 2005) guidelines. Accordingly, the adjusted IBMWP and IPtIs indexes for our study sites were "bad" for Monte Seco, "reasonable" for Quinta da Ombria and "excellent/good" for Fonte Benemola. Using this stream classification we henceforth abbreviate the stream reaches as: "BD" for Monte Seco, "RB" for Quinta da Ombria and "EX" for Fonte Benemola.

The BD $\left(37^{\circ} 11^{\prime} 18.6^{\prime \prime} \mathrm{N} 8^{\circ} 05^{\prime} 26.3^{\prime \prime} \mathrm{W}\right)$ and $\mathrm{RB}$ $\left(37^{\circ} 11^{\prime} 14.9^{\prime \prime} \mathrm{N} 8^{\circ} 04^{\prime} 52.7^{\prime \prime} \mathrm{W}\right)$ sites are located within the same stream (Algibre) which is a junction of the Menalva and Ribeira das Merces streams. The BD site is located downstream relative to RB site. Both sites have seasonal flow regimes (Williams, 2006) and are located outside the Nature Reserve. Wet periods begin in late October and generally last until March, with high discharge peaks. However, during the dry season ( $\sim$ June to September), the stream fragments into temporarily disconnected pools or completely dry channels. During steady flow conditions ( $\sim$ March to May) average discharge is $1.3 \mathrm{~m}^{3} \mathrm{~s}^{-1}$, which gradually decreases in warmer months, becoming as low as
$0.026 \mathrm{~m}^{3} \mathrm{~s}^{-1}$ at the end of the dry season ( July to August). Flow conditions were determined with weekly measurements of stream discharge at the most representative stream cross section. Annual variability in stream discharge directly affects substrate characteristics, algae and macrophyte development, and organic debris accumulation (Gasith \& Resh, 1999; Sabater et al., 2006). The mean width of both streams is $8 \mathrm{~m}$ and depth ranges from 20 to $50 \mathrm{~cm}$ in riffles and $50-100 \mathrm{~cm}$ in pools.

Riparian vegetation in the BD site is dominated by invasive wild cane (A. donax), herbaceous vegetation and carob (Ceratonia siliqua L.) and olive trees and is moderately developed with a 3-m-wide lateral zone at both sites of the stream and occasional spots of more scattered canopy cover. Estimated riparian cover for the BD site is $25 \%$. This site is used for local tourist activities, such as river safaris, and is exposed to direct impact from orange groves and olive tree plantations, which results in lower water quality status than the other sites (Chícharo et al., 2010). The intermediate $\mathrm{RB}$ site has less densely developed riparian vegetation than the BD site (20\% riparian cover), and it consists only of shrubs and herbaceous vegetation with wider and less steep riverbanks. Catchment land use is similar at both sites, except for forest, mainly consisting of olive tree plantations and orange groves; however, the proximity to Nature Reserve borders (Fig. 1) makes this site slightly less impacted than the BD site (Chícharo et al., 2010). The dominant substrate type for both the BD and RB sites is cobble and gravel.

The EX site $\left(37^{\circ} 12^{\prime} 35.0^{\prime \prime} \mathrm{N}, 8^{\circ} 00^{\prime} 38.9^{\prime \prime} \mathrm{W}\right)$ is located within a Nature Reserve, and is the most upstream and the least impacted site. It is located within a second-order stream (the Menalva). The Menalva is primarily fed by three-groundwater sources $(\sim 60 \%$ total discharge), which usually results in permanent annual flow, with the lowest discharge of $0.02 \mathrm{~m}^{3} \mathrm{~s}^{-1} \mathrm{~m}$ recorded in September and the highest of $2.75 \mathrm{~m}^{3} \mathrm{~s}^{-1}$ in January (SNIRH, 2016). Nevertheless, reduced precipitation in recent years has caused this reach to dry out during last three summers (personal observation). Mean channel width is $4.8 \mathrm{~m}$ and average channel depth varied from $26 \mathrm{~cm}$ in pools and $16 \mathrm{~cm}$ in riffles. Riparian vegetation at the EX site consists of tree and shrub species such as willow (Salix sp.), ash (Fraxinus sp.), oleander cane and African tamarisk (Tamarix sp.). Estimated 


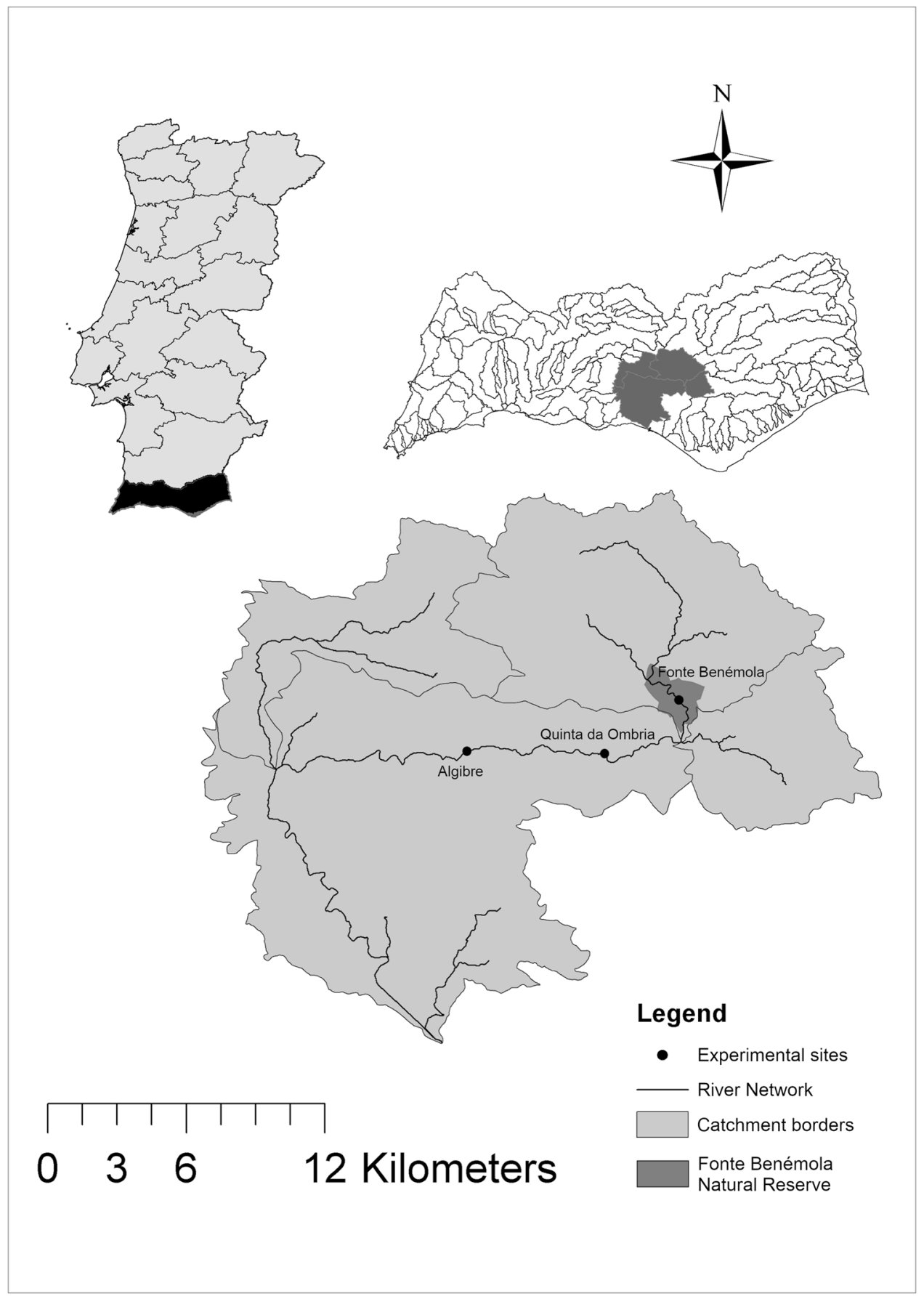

Fig. 1 Map showing the study reaches within the Quarteira River Basin in the Algarve region of southern Portugal, with the boundaries of the Fonte Benemola Nature Reserve indicated with darker shading. Three reaches are following the

riparian cover for the EX site is approximately $65 \%$. Land use is mostly agroforestry consisting of typical Mediterranean vegetation, including rosemary, anthropogenic impact gradient. Accordingly, the adjusted IBMWP and IPtIs indexes for our study sites were "bad" for Monte Seco (BD), "reasonable" for Quinta da Ombria (RB) and "excellent/good" for Fonte Benemola (EX)

strawberry trees, wild olive, cork oak (Quercus suber L.), carob trees, and almond tree (Prunus sp.) plantations. These land use characteristics together with 
scant urban development leave the EX site with a relatively undisturbed catchment, which has been classified as a Local Protected Landscape by LawDecree no. 142/2008, dated 24th of July. Because of the high water quality, a number of pollution sensitive trichopterans are present, such as, Leptoceridae, Philopotamidae, Psychomyiidae, or Polycentropodide. Benthic habitat consist mainly of boulders and coarse gravel of schist and limestone origin, covered by aquatic algae and moss. Dense canopy cover and narrow channel width with relatively steep river banks impedes light penetration and makes the EX site less productive than the other two sites.

\section{Environmental parameters and biotic variables}

We measured a number of environmental parameters that included: temperature $\left({ }^{\circ} \mathrm{C}\right)$, dissolved oxygen $\left(\mathrm{mg} \mathrm{l}^{-1}\right)$ and $\mathrm{pH}$ with a multiparametric handheld probe (YSI, Professional Plus) and photosynthetically active radiation (PAR) in $\mu \mathrm{mol}$ quanta $\mathrm{m}^{-2} \mathrm{~s}^{-1}$ (LI250A Light Meter) at each site and sampling occasion. Two to four replicate periphyton samples (each consisted of 1 large or 2 smaller stones) were collected at each site for biomass (chlorophyll $a$ and Ash free dry mass-AFDM) determination. Water samples for nutrient analysis $\left(\mathrm{NO}_{3}{ }^{-}, \mathrm{NH}_{4}{ }^{+}\right.$and $\left.\mathrm{PO}_{4}{ }^{3-}\right)$ were collected at each site and immediately frozen for posterior analysis. In the laboratory bulk periphyton from stones was scrubbed into a known volume of water using a toothbrush and thoroughly homogenized (Biggs \& Kilroy, 2000). The resultant slurry was subsampled and filtered on glass fiber filters $(\mathrm{GF} / \mathrm{C}$, $47 \mathrm{~mm}$ Whatman) for chlorophyll $a\left(\mathrm{Chl} a \mathrm{mg} \mathrm{m}^{-2}\right.$ ) and ash free dry mass (AFDM $\mathrm{mg} \mathrm{m}^{-2}$ ) analysis. Chl $a$ was extracted in $90 \%$ boiling ethanol and kept at $-20^{\circ} \mathrm{C}$ for $24 \mathrm{~h}$. Absorbance was read on a spectrophotometer (Thermospectronic GENESYS 10UV) at $665 \mathrm{~nm}$. AFDM filters were dried to constant weight at $60^{\circ} \mathrm{C}$ (dry weight) then burnt for $4 \mathrm{~h}$ at $450^{\circ} \mathrm{C}$ (Ash Weight). AFDM represents the weight difference between Dry weight and Ash Weight. Chl $a$ and AFDM were calculated per stone surface area assuming that metabolically active area of stones is $60 \%$ (Biggs \& Close, 1989). Water samples were analyzed for soluble reactive phosphorus (SRP) and ammonium spectrophotometrically (APHA, 2012). Nitrate concentrations were analyzed on a Skalar autoanalyzer (Skalar SAN Plus System, SKALAR) using the cadmium reduction method (APHA, 2012). All the water samples were filtered (GF/F, $47 \mathrm{~mm}$ Whatman) in the laboratory prior to analyses.

Basal resources and macroinvertebrates sampling for SIA

At each site the most representative stream section $(100 \mathrm{~m})$, including riffle and pool zones, was selected. Basal food sources and benthic macroinvertebrates for SIA were sampled on 10 days (March 16 to May 13, 2015) during a period of steady flow (Sroczyńska et al., 2017). We sampled study reaches on the following dates: BD 16.03, 23.03, 22.04, and 07.05; RB: 25.03, 13.04, 14.04 and EX: 25.03, 13.04, 14.04). Periphyton samples (two to four replicates) were collected from the top of randomly chosen stones and detritus in the form of conditioned leaves was sampled from detrital deposits on the stream margins. In addition to the periphyton scrubbed from stones, we also collected the first few cm layer of thick biofilm (if it was present) that had "slimy" like structure. Fine particulate organic matter (FPOM) was collected from the surface of the stream bottom with a syringe and further concentrated on a $0.53-\mu \mathrm{m}$ sieve. Filamentous algae from stones of the genus Cladophora sp., macrophytes, moss, and detritus samples were handpicked when present. All resource samples were subsequently frozen in liquid nitrogen.

We collected 10 different benthic macroinvertebrates taxa (Table 1) for SIA. These taxa were selected a priori based on their relative abundances in the reach determined by a routine sampling (Appendix-Supplementary Material 1). However, except for their abundances they were also chosen to account for a wide spectrum of functional groups and trophic positions (Table 1). Macroinvertebrates were removed from stones with forceps or elutriated from soft substrates, identified in the field to family level and left in jars for approximately $3 \mathrm{~h}$ to clear gut contents and preserved in liquid nitrogen. A minimum of three replicates for each of the 10 macroinvertebrate taxa were collected at each site resulting in a total of 100 macroinvertebrate samples for SIA. Forty-five samples were collected from the BD, 29 from the EX, and 26 from the RB site (please see provided Appendix-Supplementary Material 2). Each replicate sample was at least $100 \mathrm{mg}$ dry weight to assure enough material to be detected by the mass 
spectrophotometer. This weight corresponded to approximately 30-40 individuals for smaller taxa such as Baetidae and Dytiscidae (Oreodytes sp.), 20-30 individuals for trichopterans [Chimarra marginata (Linnaeus, 1761) in the EX and Hydropsyche sp. in the RB sites] and 10-15 individuals for the remaining taxa. The exception was crayfish [Procambarus clarkii (Girard, 1852)], for which one replicate sample consisted of a single individual. All the individuals were the same size and belonged to the same taxa.

Together with sampling for isotope analysis, each reach was also sampled for total macroinvertebrate community. The objective of the sampling for the community was to: (1) Confirm macroinvertebrate identities used for SIA and (2) determine the biomass of each of the taxa in the reach. Macroinvertebrates were sampled with a standardized kick sampling method (each sampling unit was $1 \mathrm{~m}$ long and $0.25 \mathrm{~m}$ wide) with a hand-net ( $0.5 \mathrm{~mm}$ mesh, $25 \mathrm{~cm}$ width). For each reach 4-6-m trawls (0.25 m width) were collected. Sample contents were placed in plastic containers and preserved using 96\% ethanol and further identified to family level. Consumer biomass ( $g$ ) used for further calculation of isotopic metrics was obtained by multiplying the individual dry weight by the abundance of a given taxa in the reach.

\section{Sample processing}

Basal resources and macroinvertebrates samples were lyophilized while frozen and subsequently homogenized to a fine powder using an agate mortar and pestle. Stable isotopes $\left(\delta^{13} \mathrm{C}\right.$ and $\left.\delta^{15} \mathrm{~N}\right)$ and $\%$ carbon and $\%$ nitrogen content were determined by isotope ratio mass spectrometry (IRMS). The stable carbon and nitrogen isotopic signatures were analyzed as described in González-Pérez et al. (2015). The instrumental setup consisted of the Flash 2000 HT/IRMS system (Thermo Scientific, Bremen, Germany) microanalyzer coupled via a ConFlo IV interface unit to a continuous flow (IRMS) Delta V Advantage from Thermo Scientific, Bremen, Germany. Sample $(0.5 \mathrm{mg})$, wrapped in tin foil, was combusted in an instrument furnace at $1020^{\circ} \mathrm{C}$. Isotopic ratios were expressed using $\delta$ notation where values are reported as parts per thousand (\%o) deviations from Pee Dee Belemnite (PDB) for carbon and air $\mathrm{N}_{2}$ for nitrogen standards. The standard deviation of bulk ${ }^{13} \mathrm{C}$ and ${ }^{15} \mathrm{~N}$ was typically less than $\pm 0.1 \%$.

Table 1 Feeding information about each experimental taxa based on functional feeding groups (FFG) classification (Merritt \& Cummins, 1996). "Trichoptera" consisted of Chimarra marginata in the EX and Hydropsyche sp. in the RB sites

\begin{tabular}{|c|c|c|c|c|}
\hline $\begin{array}{l}\text { Main } \\
\text { classes }\end{array}$ & Taxon & $\begin{array}{l}\text { Functional feeding } \\
\text { group }\end{array}$ & Trophic level & Presumed type of food \\
\hline \multirow[t]{6}{*}{ Insects } & Baetidae & Collector/gatherer & Herbivore & Detritus, diatoms (Merritt \& Cummins, 1996) \\
\hline & Trichoptera & $\begin{array}{l}\text { Collector/filterer/ } \\
\text { predator }\end{array}$ & Herbivore/carnivore & $\begin{array}{l}\text { Insects larvae, fine particulate organic matter (FPOM) } \\
\text { (Tachet et al., 2002) }\end{array}$ \\
\hline & Heptageniidae & $\begin{array}{l}\text { Collector/gatherer/ } \\
\text { scraper }\end{array}$ & Herbivore & Detritus, diatoms, alage (Merritt \& Cummins, 1996) \\
\hline & Perlodidae & Predator/collector & Carnivore/herbivore & $\begin{array}{l}\text { Chironomidae/Simuliidae/Ephemeroptera, but also } \\
\text { vegetal material: algae/detritus (Stewark \& Stark, } \\
\text { 1988; López-Rodríguez et al., 2012b) }\end{array}$ \\
\hline & Dytiscidae & Predator & Carnivore & Various insects (Tachet et al., 2002) \\
\hline & Coenagrionidae & Predator & Carnivore & $\begin{array}{l}\text { Cladocera/Chironomidae (Merritt \& Cummins, 1996; } \\
\text { Tachet et al., 2002) }\end{array}$ \\
\hline \multirow[t]{2}{*}{ Mollusk } & Ferrisidae & Grazer & Herbivore & Periphyton attached to algae (Merritt \& Cummins, 1996) \\
\hline & Physidae & Grazer & Herbivore & Periphyton attached to algae (Merritt \& Cummins, 1996) \\
\hline \multirow[t]{2}{*}{ Crustacean } & $\begin{array}{l}\text { Atyaephyra } \\
\text { desmarestii }\end{array}$ & Omnivore & Omnivore & Organic matter, macroinvertebrates (Tachet et al., 2002) \\
\hline & $\begin{array}{l}\text { Procambarus } \\
\text { clarkii }\end{array}$ & Omnivore & Omnivore & $\begin{array}{l}\text { Detritus/algae/other invertebrates (Gutierrez-Yurrita \& } \\
\text { Montes, 2001) }\end{array}$ \\
\hline
\end{tabular}


Isotopic metrics

The isotopic metrics were calculated according to Cucherousset \& Villéger (2015). Prior to metric calculations, mean raw isotopic values for each $\delta^{15} \mathrm{~N}$ and $\delta^{13} \mathrm{C}$ were corrected by a community centroid approach to have the same range (0-1) in order to correct for the natural variability in the isotopic values among sites with different isotopic baselines (Villéger et al., 2008). This was achieved by estimating the spatial values for isotope data by taking the mean distance of macroinvertebrate taxa from the community mean at each site, following Schmidt et al. (2011).

Scaled values of $\delta^{15} \mathrm{~N}$ and $\delta^{13} \mathrm{C}$ of each consumer were merged with their corresponding biomass data to form one matrix table for further analysis. This is important in community analysis, where individuals vary in their densities and biomasses, being not equally distributed across the trophic levels and influencing energy flux. Therefore weighting stable isotopic values by their natural abundance or biomass are ecologically more realistic. All the isotopic-derived metrics are based on the position of the organisms within a 2-D space (defined by the $\delta^{13} \mathrm{C}$ and $\delta^{15} \mathrm{~N}$ isotopes; Layman et al., 2007).

Isotopic richness (Irich) was measured by the convex hull area, which is the amount of isotopic space filled by consumer groups. Isotopic divergence (Idiv) accounts for the distribution and biomass of consumers, within the convex hull. Idiv is small (close to 0 ) when most of the points are close to the community isotopic mean (center of gravity of a convex hull), that is, when the community is dominated by consumers with similar biomass and isotopic signatures. In contrast, Idiv is high (close to 1) when the community is dominated by organisms with extreme isotopic position (i.e., large bodied predators or invasive species with extreme isotopic values). Isotopic dispersion (IDis) is low (close to 0) when all organisms have similar stable isotope signatures. In contrast, IDis is high (close to 1) when organisms have dissimilar stable isotope values, but similar biomasses in the community (i.e. large predators and primary consumers). Isotopic evenness (IEve) accounts for distance between organisms and is high when all organisms are evenly distributed in isotopic space, and low (close to 0 ) when the majority of consumers are packed within a small area of the convex hull, with few others far from this cluster. Isotopic uniqueness (IUni) measures how close consumers are in the stable isotopic space and it inversely corresponds to isotopic redundancy. IUni of 0 corresponds to maximum redundancy where all of the consumers have at least one other consumer that shares the same diet (share the same isotopic space). IUni is close to 1 when each consumer is isolated in isotopic space and there are no consumers that share the same diet. The value 1 corresponds to little redundancy, and a value of 0 corresponds to maximum redundancy. For further description of these metrics, see Cucherousset \& Villéger (2015).

\section{Bayesian mixing models}

The contribution of different food sources to consumer diet was calculated using Bayesian mixing models (SIAR; Parnell \& Jackson, 2013) in R (R Core Team, 2012). Variation in diet tissue trophic enrichment factors (per each trophic level) of stable nitrogen isotopes constitutes a major source of uncertainty in mixing models (Peterson \& Fry, 1987). We used enrichment factors for nitrogen calculated by Bunn et al. (2013) for freshwater macroinvertebrates in a broad range of Australian streams, as their taxa and ecosystems were the most similar to ours. Additionally, isotopic biplots constructed with raw isotopic values (without trophic fractionation) closely matched values reported by Bunn et al. (2013). Therefore, for herbivorous taxa we used mean $\delta^{15} \mathrm{~N}$ of $1.2 \%$ and SD $1.7 \%$, whereas for predatory consumers we used mean $\delta^{15} \mathrm{~N}$ of $+1.8 \%$ and SD of $1.7 \%$ (Bunn et al., 2013). For $\mathrm{C}$ we used $+1 \%$ and SD $0.5 \%$. The SIAR package considers normally distributed raw isotopic values of consumers, resources, and fractionation factors for each isotope and fits a Bayesian model based on Gaussian likelihood with a mixture dirichletdistributed prior on the mean (Parnell \& Jackson, 2013). As food sources varied among our study sites, the model was fitted for each site separately. "Other macroinvertebrates" represent mean values of all "herbivore-considered" macroinvertebrates that could potentially be prey for predatory consumers. To determine model performance, we calculated the correlation coefficient of posterior distributions between resources (generated by pairing simulated values of the dietary contributions drawn by each iteration of the MCMC-Markov Chain Monte Carlo process). Low correlations between sources for each 
taxa indicate that the model performed well in terms of resources differentiation. In contrast, higher correlations indicate that the model poorly differentiated between sources. If two sources are difficult to differentiate, the likely solution would involve one or another source, but not both at the same time. This is expected to show negative correlation (between these two resources) in posterior distribution correlation plots (Appendix-Supplementary Material 4). Positive correlations are possible when a solution that involves one source, but also needs another source in some proportion to balance each other out. The correlation coefficients were obtained using "siarmatrixplot" function in SIAR (Parnell \& Jackson, 2013).

\section{Results}

Environmental parameters and biotic variables

Environmental and biotic variables are presented in Table 2. PAR was the highest for the BD and RB sites, which had the lowest riparian cover. In contrast, the EX site had the lowest mean PAR and the lowest minimum PAR value. Nutrients $\left(\mathrm{NO}_{3}, \mathrm{PO}_{4}, \mathrm{NH}_{4}\right)$ had generally low values with the exception of $\mathrm{NO}_{3}$, which was higher in the EX site compared with other two sites (Table 2). $\delta^{15} \mathrm{~N}$ and $\delta^{13} \mathrm{C}$ of consumers and their basal resources

Biplots indicate a general tendency toward higher $\delta^{13} \mathrm{C}$ and $\delta^{15} \mathrm{~N}$ variation in basal food sources (predominantly periphyton) relative to consumers (Fig. 2). In general, most of the studied taxa tracked their food sources and consequently the depletion in $\delta^{13} \mathrm{C}$ and $\delta^{15} \mathrm{~N}$ of periphyton follows the depletion in consumers (Fig. 2). Nevertheless, the majority of sampled taxa were significantly more depleted in ${ }^{13} \mathrm{C}$ than their presumed food sources and this was consistent among the three study sites. Consumer $\delta^{13} \mathrm{C}$ values at the least impacted site (EX) had the highest within-site variation in comparison with the $\mathrm{RB}$ and the BD sites. The RB site had the highest $\delta^{15} \mathrm{~N}$ values for both basal resources and consumers. The BD site showed slightly lower $\delta^{15} \mathrm{~N}$ values, and the EX site had the lowest overall $\delta^{15} \mathrm{~N}$ values (for both basal resources and consumers; Fig. 2). This variability in isotopic baselines among sites confirms that raw isotopic values were not directly comparable among different sites. Within each site predators had generally higher values of $\delta^{15} \mathrm{~N}$ and the lowest values were reported for mollusks. Interestingly collector-gatherers had $\delta^{15} \mathrm{~N}$ values more similar to predators than to herbivores (mollusks; Appendix-Supplementary Material 3). Bulk periphyton $\delta^{15} \mathrm{~N}$ and $\delta^{13} \mathrm{C}$ was highly variable at all sites (Fig. 2, Appendix-Supplementary Material 3). The isotopic $\mathrm{C} \delta^{13}$ and $\mathrm{N} \delta^{15}$

Table 2 Mean values of main biotic and environmental variables recorded at each studied site

\begin{tabular}{lccc}
\hline Measured parameters & Monte Seco (BD) & Quinta da Ombria (RB) & F. Benemola (EX) \\
\hline PAR $(\mu \mathrm{E} \mathrm{m-2} \mathrm{s-1)}$ & $2476.01(1600.47-3226.23)$ & $2817.80(2617.80-3088.52)$ & $2348.21(1332.08-2876.35)$ \\
pH & $8.00(7.5-8.36)$ & $7.70(7.26-8.06)$ & $7.79(7.43-8.15)$ \\
Dissolved oxygen $(\mathrm{mg} 1-1)$ & $8.79(6.66-11.2)$ & $8.24(6.44-10.47)$ & $9.16(6.25-11.8)$ \\
Temperature $\left({ }^{\circ} \mathrm{C}\right)$ & $16.83(15.00-20.05)$ & $17.88(16.00-20.15)$ & $16.24(15.40-18.00)$ \\
NH4+-N $(\mu \mathrm{M})$ & $0.26(0.00-0.65)$ & $0.53(0.00-1.91)$ & $1.05(0.62-1.32)$ \\
NO3-N $(\mu \mathrm{M})$ & $5.71(1.93-6.82)$ & $3.39(2.03-4.64)$ & $18.80(3.46-30.60)$ \\
PO4 -P $(\mu \mathrm{M} 1)$ & $0.05(0.00-0.13)$ & $0.03(0.00-0.14)$ & $0.15(0.00-0.28)$ \\
Chlorophyll a $(\mathrm{mg} \mathrm{m}-2)$ & $250.7(75.3-610.6)$ & $145(29.0-441.0)$ & $205.3(35.1-532.9)$ \\
AFDM $(\mathrm{g} \mathrm{m}-2)$ & $37.32(12.49-59.75)$ & $28.94(2.62-53.46)$ & $45.03(5.98-93.40)$ \\
Chlorophyll a/AFDM & $0.008(0.003-0.030)$ & $0.009(0.001-0.030)$ & $0.005(0.003-0.009)$ \\
N dry mass $(\mathrm{g} \mathrm{m}-2)$ & $104.58(39.17-219.87)$ & $64.33(58.86-69.80)$ & $162.91(40.29-389.24)$ \\
C dry mass $(\mathrm{g} \mathrm{m}-2)$ & $2530.29(1722.16-3832.75)$ & $1231.96(1016.40-1447.53)$ & $1904.25(494.03-5920.33)$ \\
\hline
\end{tabular}

Minimum and maximum values are in brackets 


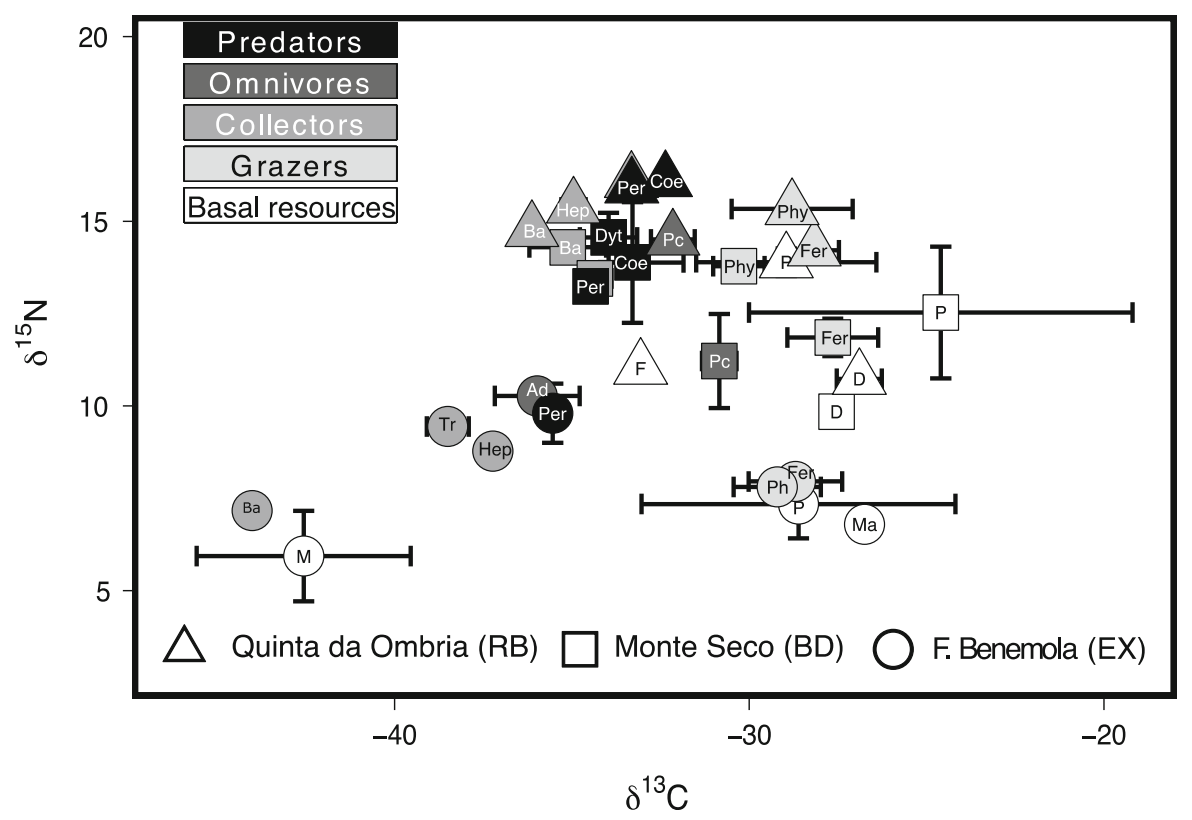

Fig. 2 Biplots of carbon $\left(\delta^{13} \mathrm{C}\right)$ and nitrogen $\left(\delta^{1-5} \mathrm{~N}\right)$ isotopic signatures (representing mean and standard deviation) for each taxa with colors depicting different FFGs assignment (according to Merritt and Cummins (1996) and Tachet et al. (2002)), at our three study reaches. Basal food resources were: D-detritus;

signature found in detritus collected from the BD and RB sites varied little with mean values of $10.5 \pm 0.57$ and $-27.1 \pm 0.58 \%$ for $\delta^{15} \mathrm{~N}$ and $\delta^{13} \mathrm{C}$, respectively (Appendix-Supplementary Material 3). FPOM collected only from RB site had the highest values reported for detritus ( $\delta^{15} \mathrm{~N} 11.2 \%$ and $\delta^{13} \mathrm{C}-33.1 \%$ ). Macrophytes were collected only from EX site and had values 6.63 for $\delta^{15} \mathrm{~N}$ and -28.32 for $\delta^{13} \mathrm{C}$ (Appendix-Supplementary Material 3). This was also reflected in the general architecture of the resource diversity (Fig. 3A). The BD site had the highest resource diversity, which was mainly due to large variability in periphyton (Fig. 3A). In contrast, the RB site had the smallest resource diversity which was attributed to detritus and FPOM, which had a distinctly different isotopic composition than periphyton. In EX site, moss had a very different isotopic composition from the remaining resources and was responsible for generally higher resource diversity within this reach (Fig. 3A).
F-fine particulate organic matter; Ma-macrophytes; Mmoss; P-Periphyton. Taxa were: Ad-Atyaephyra desmarestii, Ba-Baetidae, Coe-Coenagrionidae, Dyt-Dytiscidae, FerFerrisidae, Hep-Heptageniidae, Per-Perlodidae, Pc-Procambarus clarkii, $\mathrm{Ph}$-Physidae, $\mathrm{Tr}$ - Trichoptera

Food web characteristics and isotopic metrics

Trophic distribution was the highest at the EX site, and lowest at the RB site (Fig. 3B). Corresponding isotopic richness was the highest at the EX site (0.152) comparable to the RB (0.061) and BD (0.08) sites (Fig. 4). Most macroinvertebrate biomass (associated with invasive $P$. clarkii) was distributed among high trophic levels in the more impacted BD site, while macroinvertebrate biomass was more uniformly distributed among trophic levels in least impacted EX site (Fig. 3B). At the intermediate RB site, biomass was clearly associated with $P$. clarkii and the highly abundant Baetidae family. This translated to high isotopic divergence (0.978) in BD. Isotopic divergence was also high at the EX site, closely associated with the very abundant Baetidae family, and with extreme isotopic values that pushed the convex hull toward top right corner (Figs. 3B, 4). Isotopic dispersion followed the impact gradient and was highest in the least impacted EX site (0.422), lower at the intermediate RB site (0.315) and the lowest at the most impacted BD site (0.149). Similarly, isotopic uniqueness that inversely corresponds to redundancy 


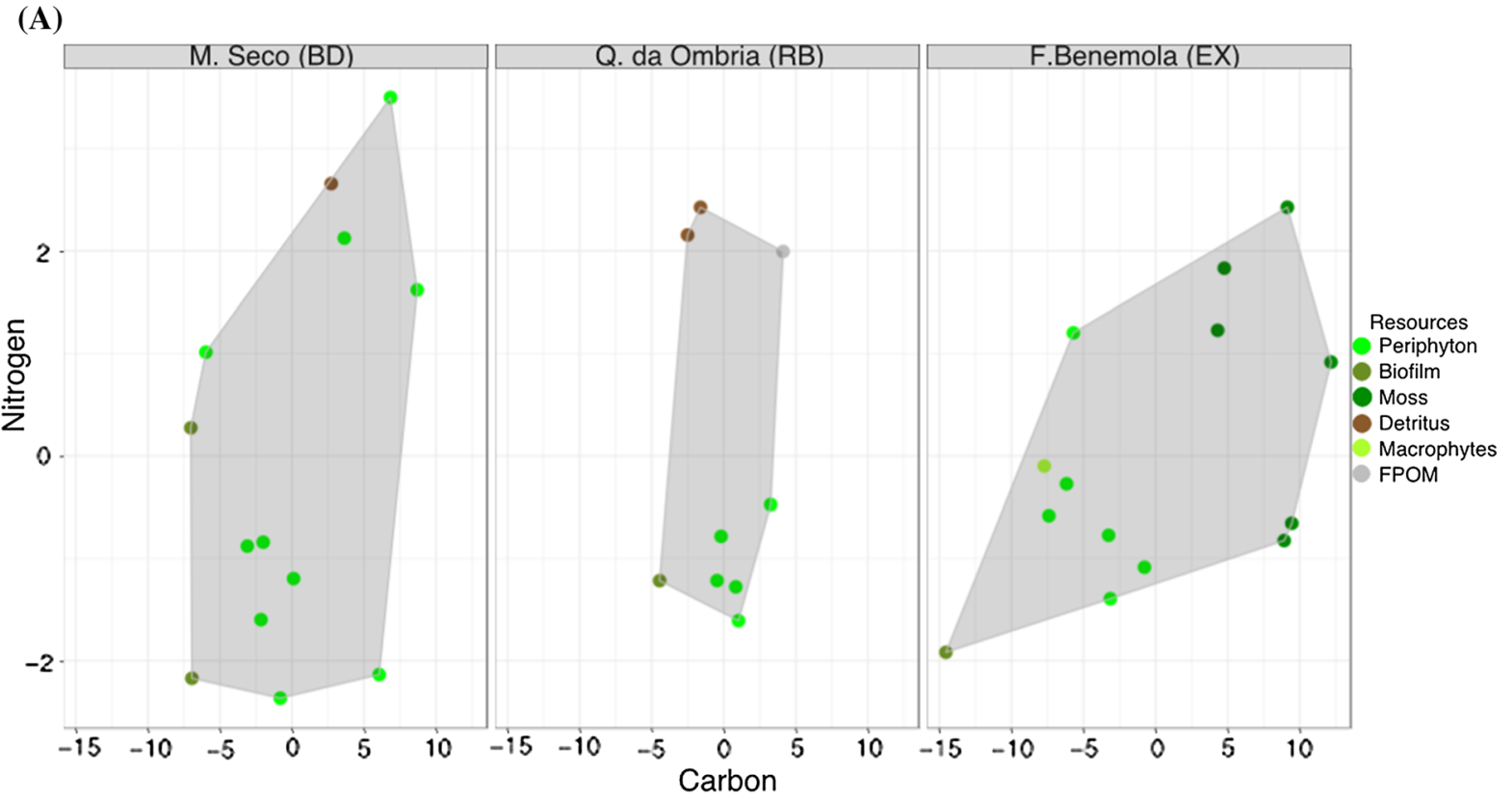

(B)

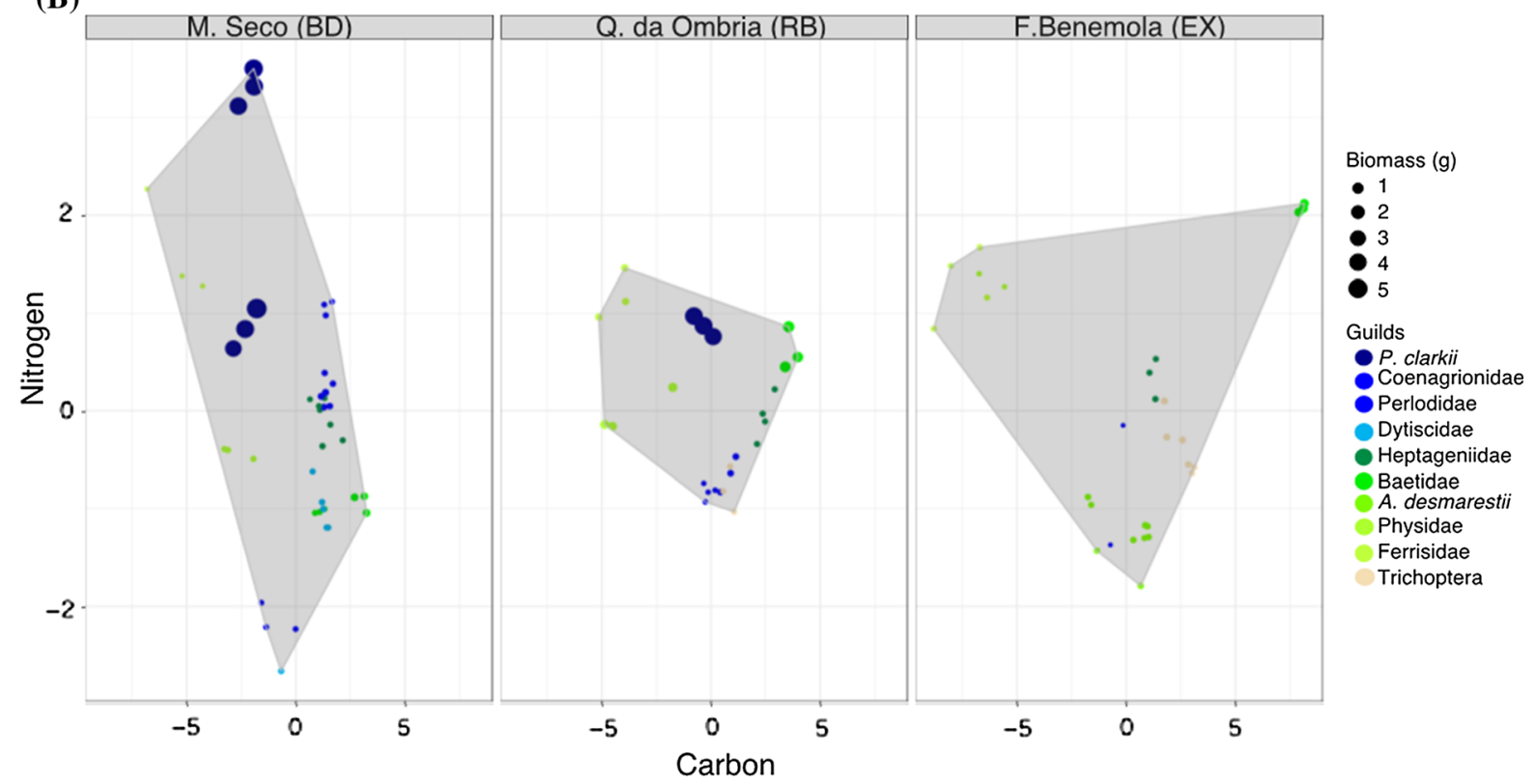

Fig. 3 Trophic distribution of the basal resources (A) and macroinvertebrates community $(\mathbf{B})$ at each stream corrected by a community centroid, where isotope data were converted to spatial data. Each data point is expressed as the average distance from the community isotope mean $(0.0)$ for both the carbon and nitrogen axis. Therefore, the further a point is from 0.0 , the more dissimilar its trophic ecology is in comparison with the community average. Larger convex hulls, therefore, represent more diverse communities in terms of resource heterogeneity
(A) and their trophic ecology (B). In B (trophic distribution of consumers), the size of each point represents biomass of the macroinvertebrates taxa (i.e., larger points represent higher biomass of a given taxa). For better visualization the blue colors represent predatory/omnivory guilds, green represents herbivory (collectors and grazers), and beige represents the prevalence of filter feeding (according to Merritt and Cummins (1996)) 


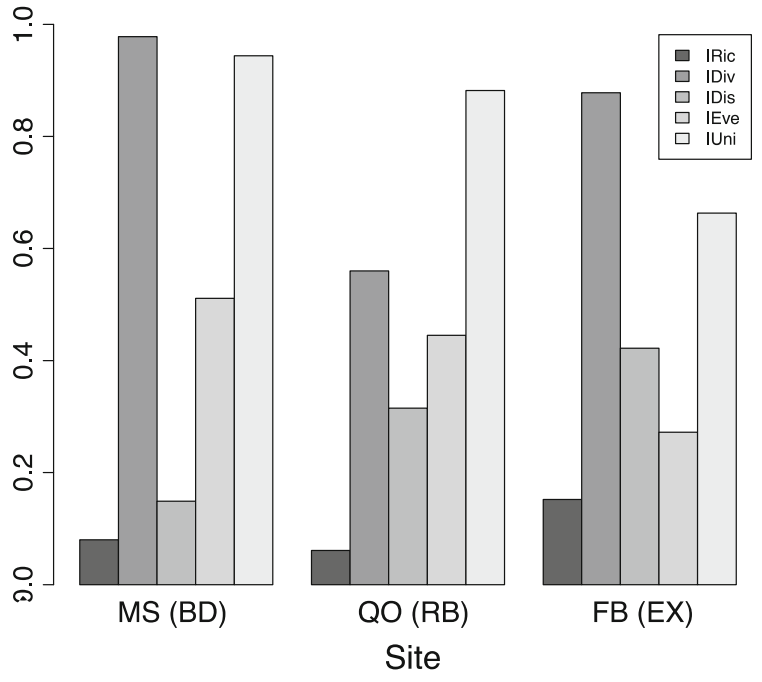

Fig. 4 Isotopic metrics for the three study reaches Monte Seco (BD), Quinta da Ombria (RB) and the Fonte Benemola (EX). Isotopic metrics include Isotopic richness (IRich), Isotopic divergence (IDiv), Isotopic dispersion (IDis), Isotopic evenness (IEve), and Isotopic uniqueness (IUni)

demonstrated that the more impacted BD and RB sites had very low redundancy, relative to the EX site (Fig. 4). Trophic distribution demonstrated no clear pattern in terms of predator-herbivore-filter feeder distribution in the convex hull biplot. In the BD and RB sites, higher trophic levels were clearly occupied by $P$. clarkii, but the rest of predatory taxa occupied similar trophic levels as consumers from other trophic groups (collectors, scrapers, and filterers).

Food source for aquatic consumers

Results from SIAR indicate that periphyton, other macroinvertebrates and to a lesser degree detritus were the primary contributions to consume diet (Fig. 5). In turn biofilm, FPOM and macrophytes were rarely used as a food source. Nevertheless, high variability, particularly in periphyton, detritus and other macroinvertebrates made it difficult for the mixing model to distinguish among specific resources (AppendixSupplementary Material 4). At the impacted BD site the majority of taxa mostly relied on periphyton, and a mixture of periphyton and other macroinvertebrate consumers. While the herbivore Physidae were highly depended on periphyton, other mollusks such as Ferrisidae relied also in a large degree on detritus (Fig. 5). Dytiscidae and Coenagrionidae were clearly demonstrated to be predators in this ecosystem. However, it was possible to distinguish another population of Coenagrionidae at this site that also relied on algae and was located at lower trophic level (Fig. 5). In the less impacted RB site, detritus contributed to a lesser extent of consumer diets. Omnivorous $P$. clarkii at this stream demonstrated lesser dependence on other macroinvertebrates, but more on FPOM, and some periphyton. Mollusks where clearly separated from other consumers as they largely relied on periphyton. In the RB site, it was possible to better distinguish different trophic levels within the omnivorous/predatory consumers. Baetidae occupied the lowest trophic level, whereas Heptageniidae, Trichoptera, and Coenagrionidae occupied the highest trophic position as top predators. In the least impacted EX site, lack of detritus was substituted by moss, which almost exclusively contributed to the Baetidae diet. Similarly as in other sites, mollusks fed on periphyton, which distinguished them from the rest of the carnivorous consumers, that relied mostly on other macroinvertebrates and to a lesser extent on moss. Within predatory/omnivory taxa Heptageniidae and Trichoptera were located at the lowest trophic level, obtaining their energy from both moss and some macroinvertebrates. Whereas Atyaephyra desmarestii (Millet, 1831) were located at the highest trophic level. However, a high posterior distribution correlation coefficient for moss and other macroinvertebrates, particularly for A. desmarestii at this reach, indicates uncertainty in which of these two resources contributes to real macroinvertebrate diets (AppendixSupplementary Material 4). Biofilm and to a lesser extent macrophytes did not contribute as a food source to any of the macroinvertebrate taxa. Beside high variability in basal resources it was possible to conclude that most of the studied taxa fed on a mixture of periphyton and other macroinvertebrates, indicating more generalistic feeding habits. We found more omnivory in the BD site in comparison with the other sites, that was reflected in a higher number of consumers occupying the same trophic level.

Additionally, some taxa displayed changes in their dietary habits depending on site (i.e., Baetidae, Ferrisidae), which clearly demonstrates the importance of local resource heterogeneity on consumer diets. 

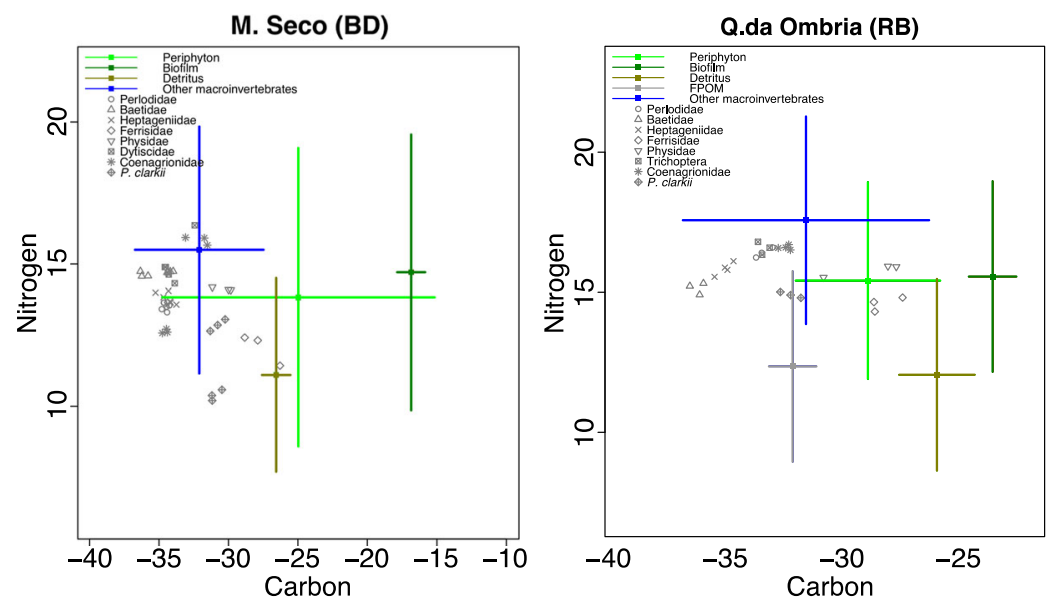

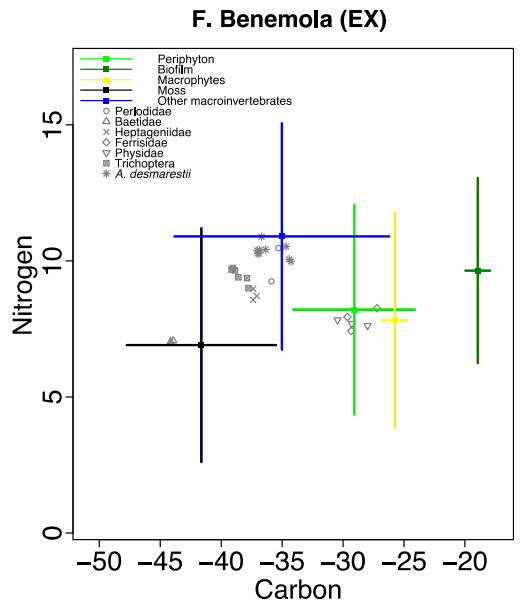

Fig. 5 Biplots of carbon $\left(\delta^{13} \mathrm{C}\right)$ and nitrogen $\left(\delta^{15} \mathrm{~N}\right)$ isotopic signatures for each taxa (data points) and their basal food resources (colors). Error bars represent 95\% confidence intervals and incorporate the error in the source isotopic

\section{Discussion}

$\delta^{15} \mathrm{~N}$ and $\delta^{13} \mathrm{C}$ of consumers and their basal resources

Large variability in isotopic $\delta^{13} \mathrm{C}$ and $\delta^{15} \mathrm{~N}$ was observed within and among sites in both basal resources and consumers. Large within-site $\delta^{13} \mathrm{C}$ variability is commonly observed for aquatic algae in stream ecosystems (Winterbourn et al., 1986; Hamilton \& Lewis, 1992; Rosenfeld \& Roff, 1992; France, 1995). Factors that regulate carbon uptake by aquatic producers, such as water velocity, light, and temperature (Sackett et al., 1965; Osmond et al., 1981; Wienke \& Fisher, 1990; Finlay et al., 1999; Ishikawa et al., 2012), are rarely constant within a reach and their variation in turn affects algal $\delta^{13} \mathrm{C}$ values (Rosenfeld \& Roff, 1992). Among site variation in $\delta^{13} \mathrm{C}$ was higher than within-site. This result can be associated with differences in geochemical properties of the water, but also riparian cover density or differences in periphyton community composition (Finlay et al., 1999; Palmer et al., 2001; Finlay, 2004).

We reported an almost twofold $\delta^{15} \mathrm{~N}$ isotopic enrichment in the more open BD and RB sites (25\% and $20 \%$ canopy cover, respectively) in comparison with the highly ${ }^{15} \mathrm{~N}$-depleted signature found in periphyton at the EX site, which had much higher canopy cover $(65 \%)$. Generally, periphyton $\delta^{15} \mathrm{~N}$ should reflect the available nitrogen pool (Macko signatures and trophic enrichment factors (taken from Bunn et al., 2013). The biplots represent the mixing model output (SIAR; Parnell \& Jackson, 2013)

et al., 1987), indicating as expected, that the BD and RB sites receive higher nutrient inputs from surrounding fields. Use of fertilizers by increasing nitrification leads to soil $\delta^{15} \mathrm{~N}$ enrichment (Bateman \& Kelly, 2007) and consequently ends up in the streams, where it is incorporated into food webs, thereby changing the $\delta^{15} \mathrm{~N}$ available in food resources and consumers (Broderius, 2013).

In contrast, the EX site is located within a Nature Reserve, and is characterized by a more forested landscape with organic-poor alluvial soils, where soilstream nutrient exchange is restricted. We remain unable to resolve the paradoxically higher $\mathrm{NO}_{3}$ concentration in the EX site relative to the RB site (Table 2), despite its limited nutrient input and depleted $\delta^{15} \mathrm{~N}$ signature. Previous studies on this stream (Sroczyńska et al., 2017) did not record similarly high $\mathrm{NO}_{3}$ concentrations. Presumably, highly depleted basal resources and consumers in the EX site reflect a time-integrated measure of nitrogen sources, accumulated over larger periods of time, whereas higher $\mathrm{NO}_{3}$ measured in the field reflected a more temporary situation. Further, the generally low concentrations of $\mathrm{NH}_{4}$ and $\mathrm{NO}_{3}$ across the study reaches suggest that processes such as denitrification or $\mathrm{N}$ fixation may contribute to some of the variation in $\delta^{15} \mathrm{~N}$ we observed (Diebel \& Vander Zanden 2009). For example, the presence of $\mathrm{N}_{2}$-fixing cyanobacteria will decrease the epilithon $\delta^{15} \mathrm{~N}$, as atmospheric $\mathrm{N}_{2}$ is highly depleted (Hamilton \& Lewis, 1992; France 
et al., 1998). Consequently, depleted $\delta^{15} \mathrm{~N}$ values at the EX site could be associated with a higher abundance of cyanobacteria at this site.

Food web characteristics and isotopic metrics

The theoretical framework for trophic ecology is that disturbances concentrate energy fluxes on a smaller number of species and feeding paths. This creates simpler food webs, which are more vulnerable and less resistant to further environmental change (Tylianakis et al., 2007). Accordingly, we expected to find simpler food webs with increasing anthropogenic impact. Our results demonstrated that indeed the most pristine EX site, located inside Natural Reserve, had the highest isotopic richness and isotopic dispersion reflected in relatively equilibrated consumer trophic distribution.

Food web disturbances have been demonstrated to lower biodiversity of predatory species, leading to trophic downgrading (Layer et al., 2010; Estes et al., 2011; Ledger et al., 2013). Trophic cascades can follow the increase in consumer biomass, like small herbivores, in lower trophic levels. Although isotopic dispersion was smaller for the RB and BD sites, respectively, we did not observe a cascade effect along the anthropogenic impact gradient. Except for large crayfish, the predator and herbivore biomass was mostly balanced, suggesting certain resilience of these ecosystems to trophic cascades. However, we detected several other effects of the increased impact gradient on community food web.

The index of isotopic divergence was very high for the BD site, which was attributed to the extreme isotopic values of invasive crayfish. Two populations of crayfish in the BD site had highly controlling role, dominating the higher trophic levels of the community. The effect of the invasive $P$. clarkii on native communities has been reported to be stronger than native predators (Ficetola et al., 2012). Features such as large body size and ability to explore various types of resources allow $P$. clarkii to maintain high densities. Young crayfish are carnivorous (Gutierrez-Yurrita $\&$ Montes, 2001) while adults can shifts to detritus and plant based diet. Therefore, high generalism of $P$. clarkii in resource exploitation allows it to maintain high densities, even if prey is scarce. Extreme isotopic values of $P$. clarkii at the BD site are responsible for higher chain length and high trophic dispersion, also observed by Cucherousset et al. (2012). Similar findings were reported in coastal waters affected by organic and inorganic discharge (O'Gorman et al., 2012) where authors reported higher food chain length that they attributed to the dominance of a large generalist predator. These tolerant predators benefit from the increased primary production and basal resources that in turn enhance number of available prey (i.e., grazers). The BD site also had the highest basal resource standing stock (as demonstrated by available $\mathrm{C}$ stock) and was the most productive site. The fact that we did not report higher prey biomass, in comparison with the other two sites, could potentially confirm a highly controlling role of $P$. clarkii at this site.

Accordingly, we could expect that crayfish in this ecosystem may have a potential buffering role on the effect of trophic downgrading, making this ecosystem more resilient to disturbance, e.g., progressive drought (McHugh et al., 2015). In the RB site P. clarkii had less impact than in the BD site, with smaller isotopic divergence and some niche sharing with other consumers. The question of the relative impact of $P$. clarkii in these streams should be further investigated, for example examining niche overlap (Jackson et al., 2012) of $P$. clarkii and other consumers may help understand if $P$. clarkii outcompetes other native predatory consumers for resources at this site. However, given the omnivorous habits of $P$. clarkii, nonlimiting periphyton resources, and similar biomass equilibrium between smaller herbivores and larger macroinvertebrate predators, it is likely that $P$. clarkii does not necessarily interfere with the trophic structure of these reaches. On the other hand, it can have an overall negative effect on biodiversity through predation of indigenous predatory species as was observed by Ilhéu et al. (2007).

Although the RB was moderately impacted site, it had the simplest food web, where most consumers with comparable biomass shared an isotopically similar trophic niche. This was also followed by little variability in food resources. Resource heterogeneity such as the relative availability of allochthonous or autochthonous basal sources influences functional feeding traits composition and thus food web structure (Ceneviva-Bastos et al., 2017). The RB site had the smallest within-site variation of periphyton and the smallest convex hull in terms of isotopic richness, indicating that lower basal resource heterogeneity 
would follow a decrease in isotopic heterogeneity of consumers (Dézerald et al., 2018).

Trophic uniqueness decreased along the impact gradient, demonstrating higher isotopic redundancy at the least impacted EX site in comparison with the other two sites. In contrast, lower redundancy at the RB and BD sites was reflected in lessened proximity of consumers in the isotopic space. This finding can be again attributed to effect of large crayfish whose extreme isotopic values and exceptionally large biomass increased overall isotopic uniqueness of both sites.

Besides these differences, the overall IUni for all of the sites was high (more than 0.6) indicating that at least half of the consumers were isolated in isotopic space. Nevertheless, we could not attribute these differences to differences in the feeding guilds or trophic positions. Except for the crayfish, we observed across all of the sites that predators had not necessarily the highest $15 \mathrm{~N}$ values. For example in the BD site species commonly considered to be predatory shared a similar trophic niche as filter feeders, while herbivores and collector-gatherers had higher trophic position than predators (Figs. 2, 3). Similarly, collector mayflies (Baetidae and Heptageniidae) in the RB and BD sites had comparable or higher $\mathrm{N}$ signatures than $\mathrm{N}$ isotopic values of predators (Fig. 3B).

Increasing anthropogenic disturbance was demonstrated to decrease biodiversity and enhance the abundance of fewer dominant species with more generalistic feeding (Layer et al., 2010, Garcia et al., 2017). We could not link the generalistic feeding to the impact gradient, as consumers at all of the sites displayed generalistic habits. Perhaps it is more related to the temporary manner of the studied reaches. Reduction in hydrodynamic flow was demonstrated to strongly affect macroinvertebrates feeding patterns. For example, consumers inhabiting unstable environments where food resources are seasonally variable are known to adopt omnivory and generalistic feeding to utilize resources more efficiently (Lewis et al., 2001; Sánchez-Carmona et al., 2012; Blanchette et al., 2014; Arcagni et al., 2015). Nevertheless, we observed that invasive crayfish were present and influenced all of the studied metrics at sites with lower water quality. If consumer biomass was not accounted in the metrics calculation, these effects might have been outlooked.
Food source for aquatic consumers

Our predictions assumed that omnivory would increase along the impact gradient, as a result of shorter and simpler food webs. This would result in greater isotopic overlap between consumers on the biplot (Minagawa \& Wada, 1984). We indeed found the highest overlap of consumers at the most impacted site; however, we could not generalize this pattern across all the sites. In fact, the moderately impacted RB had the least overlap among consumers and clearly distinguished trophic levels.

The extent of omnivory among stream consumers is widely acknowledged, especially in streams that experience rapid changes in hydrological regime, such as temporary streams (Bunn et al., 1999; Douglas et al., 2005; Pusey et al., 2010). It is generally thought that algae or periphyton are the dominant food for scrapers, whereas collector-gatherers rely mostly on detritus and predators depend indirectly on both algal and terrestrial sources of carbon (Merritt \& Cummins, 1996). Our data is consistent with these studies, indicating that the studied organisms depended on a mixture of basal resources. Overlapping isotopic signatures mainly among $\delta^{15} \mathrm{~N}$ of periphyton and detritus, within concomitant high correlation coefficients between both components (particularly in the BD site) impeded our ability to draw conclusions on quantitative contributions of the mentioned food sources to diet of consumers. Also, most of our consumers were highly depleted in ${ }^{13} \mathrm{C}$ relative to their basal resources. This could suggest that most macroinvertebrates feed or assimilate only a portion of the actively cycling (easily absorbable) fraction of periphyton or FPOM, with depleted in $\delta^{13} \mathrm{C}$ and enriched in $\delta^{15} \mathrm{~N}$ values. We also cannot exclude the possibility that some specific resources were overlooked while sampling or constituted an unaccounted portion of a bulk of periphyton (Rezanka \& Hershey, 2003). Species are known for their capacity to switch resources in response to disturbance and environmental perturbation (Mihuc, 1997). Alterations in hydrological period in the intermittent streams follow rapid changes in resource availability and quality, and we believe that it triggers an opportunistic response of animals (at the individualistic level) to adapt to these new resources. One of the mechanisms by which consumers adapt to this variability in basal resources is selective ingestion (Dodds et al., 2014) widely 
reported in the literature (Rosenfeld \& Roff, 1992; Mulholland et al., 2000; Rezanka \& Hershey, 2003; McNelly et al., 2006). This is because bulk periphyton samples often contain a mixture of slowly and actively cycling $\mathrm{N}$, the latter being preferentially assimilated by consumers (Tank et al., 2000; Hamilton et al., 2001; Peipoch et al., 2012; Dodds et al., 2014). Complementary analysis of fatty acids or DNA sequencing have potential promise for the improvement of diet estimations (Nielsen et al., 2018). Local specialization of some taxa can often reflect the quality of food resources (Mulholland et al., 2000; McNelly et al., 2006). For example, moss was found to be an important food source for Baetidae taxa. Moss can have high phenolic content and is often considered an unpalatable and unimportant food source for stream invertebrates (Bunn et al, 1989). However, herbivores and shredders from less productive and nutrientlimited streams can switch from epilithic algae to marginal food sources such as bryophytes in times of scarcity (McWilliam-Hughes et al., 2009). In our case, we associate this finding to high nutritional value of moss, as indicated by a low $\mathrm{C}: \mathrm{N}$ ratio (mean value of 11.66-Appendix-Supplementary Material 2). A low $\mathrm{C}: \mathrm{N}$ may have made this food source more attractive to local collector-gatherers relative to less nutritional periphyton at this reach (mean $\mathrm{C}: \mathrm{N}$ ratio of 26.25-Appendix-Supplementary Material 2). This finding suggests that the importance of moss in freshwater food webs should not be underestimated.

\section{Final remarks}

Mediterranean-type streams and other water bodies with seasonal hydrodynamics are often first to suffer from climate induced premature drought. Trophic interactions are essential to predict the stability of these ecosystems in response to these perturbations (Gray et al., 2014). Isotopic indices were useful in identifying differences in the food web architecture of these three reaches, considering the biomass of studied taxa. The least impacted EX site had the highest isotopic richness, dispersion, and isotopic redundancy. The effect of disturbance on food webs in more impacted BD and RB sites was masked by the presence of invasive crayfish, which increased trophic length and trophic dispersion in the $\mathrm{BD}$, but not in the $\mathrm{RB}$ site. Invasive crayfish in these ecosystems might have a functional compensation role when the abundance of top native predators decreases because of a lengthened drought period (Ledger et al., 2013). Omnivory and local diet specialization was found as another stabilizing force in this ecosystem allowing for the use of resources more efficiently. Further understanding of food web complexity along particular stressors applied in geographically different areas is needed to support the management of these ecosystems.

Acknowledgements The authors specially acknowledge Paulo Zaragosa Pedro, Marta Ribeiro e Bruno Garcia from Laboratório de Análises Quimicas (LAQ) from University of Algarve for their technical support in chemical analysis of nutrients. We also acknowledge Alba Carmona Navarro from IRNAS-CSIC for her assistance with isotopic analysis. The following work was a part of the IMPACT project funded by Foundation for Science and Technology (FCT) of Portugal (ERA558IWRM/0003/2009).

\section{References}

Acuña, V., M. Hunter \& A. Ruhí, 2017. Managing temporary streams and rivers as unique rather than second-class ecosystems. Biological Conservation 211: 12-19.

Álvarez, M. \& I. Pardo, 2009. Dynamics in the trophic structure of the macroinvertebrate community in a Mediterranean, temporary stream. Aquatic Sciences 71: 202-213.

APHA, 2012. Standard Methods for the Examination of Water and Wastewater, 20th ed. American Public Health Association, Washington, DC.

Arcagni, M., A. Rizzo, L. M. Campbell, M. A. Arribére, R. Juncos, M. Reissig, K. Kyser, J. P. Barriga, M. Battini \& S. R. Guevara, 2015. Stable isotope analysis of trophic structure, energy flow and spatial variability in a large ultra oligotrophic lake in Northwest Patagonia. Journal of Great Lakes Research 41: 916-925.

Bateman, A. S. \& S. D. Kelly, 2007. Fertilizer nitrogen isotope signatures. Isotopes in Environmental and Health Studies 43: 237-247.

Biggs, B. J. F. \& M. E. Close, 1989. Periphyton biomass dynamics in gravel bed rivers: the relative effects of flows and nutrients. Freshwater Biology 22: 209-231.

Biggs, B. J. \& C. Kilroy, 2000. Stream periphyton monitoring manual. National Institute of Water and Atmospheric Research, Christchurch.

Blanchette, M. L., A. M. Davis, T. D. Jardine \& R. G. Pearson, 2014. Omnivory and opportunism characterize food webs in a large dry-tropics river system. Freshwater Science 33: 142-158.

Broderius, C., 2013. Anthropogenically altered land and its effect on d15 $\mathrm{N}$ values in periphyton on a fourth order stream inUtah's Cache Valley. Natural Resources and Environmental Issues 18: 61-69. 
Bunn, S. E., D. R. Barton, H. N. Hynes, G. Power \& M. A. Pope, 1989. Stable isotope analysis of carbon flow in a tundra river system. Canadian Journal of Fisheries and Aquatic Sciences 46: 1769-1775.

Bunn, S. E., P. M. Davies \& T. D. Mosisch, 1999. Ecosystem measures of river health and their response to riparian and catchment degradation. Freshwater Biology 41: 333-345.

Bunn, S. E., C. Leigh \& T. D. Jardine, 2013. Diet-tissue fractionation of $\delta 15 \mathrm{~N}$ by consumers from streams and rivers. Limnology and Oceanography 58: 765-773.

Cardinale, B. J., J. E. Duffy, A. Gonzalez, D. U. Hooper, C. Perrings, P. Venail, et al., 2012. Biodiversity loss and its impact on humanity. Nature 486: 59.

Ceneviva-Bastos, M., C. G. Montaña, C. M. Schalk, P. B. Camargo \& L. Casatti, 2017. Responses of aquatic food webs to the addition of structural complexity and basal resource diversity in degraded Neotropical streams. Australian Ecology 42: 908-919.

Chicharo, L. M. Z., F. Leitão, I. Máximo, R. Ben Hamadou, M. Moreira da Silva. 2009. Caracterização da Qualidade Ecológica da Água das Ribeiras do Algarve-Macroinvertebrados bentónicos como bioindicadores. Relatório de Monitorização Relativo ao ano de 2009.

Chicharo, L. M. Z., F. Leitão, I. Máximo, R. Ben Hamadou, M. Moreira da Silva \& A. Furtado, 2010. Caracterização Sazonal da Qualidade Ecológica da Água das Ribeiras do Algarve: Ribeira de Quarteira/Algibre e Ribeira da Seixe. ICCE-International Center for Coastal Ecohydrology, Faro, Portugal.

Coll, M., A. Schmidt, T. Romanuk \& H. K. Lotze, 2011. Foodweb structure of seagrass communities across different spatial scales and human impacts. PLoS ONE. https://doi. org/10.1371/journal.pone.0022591.

Cucherousset, J. \& S. Villeger, 2015. Quantifying the multiple facets of isotopic diversity: new metrics for stable isotope ecology. Ecological Indicators 56: 152-160.

Cucherousset, J., S. Blanchet \& J. D. Olden, 2012. Non-native species promote trophic dispersion of food webs. Frontiers in Ecology and the Environment 10: 406-408.

Dézerald, O., D. S. Srivastava, R. Céréghino, J. F. Carrias, B. Corbara, V. F. Farjalla, et al., 2018. Functional traits and environmental conditions predict community isotopic niches and energy pathways across spatial scales. Functional Ecology 32: 2423-2434.

Diebel, M. W. \& M. J. V. Zanden, 2009. Nitrogen stable isotopes in streams: effects of agricultural sources and transformations. Ecological Applications 19: 1127-1134.

Dodds, W. K., S. M. Collins, S. K. Hamilton, J. L. Tank, S. Johnson, J. R. Webster, et al., 2014. You are not always what we think you eat: selective assimilation across multiple whole-stream isotopic tracer studies. Ecology 95: 2757-2767.

Douglas, M. M., S. E. Bunn \& P. M. Davies, 2005. River and wetland food webs in Australia's wet-dry tropics: general principles and implications for management. Marine and Freshwater Research 56: 329-342.

Estes, J. A., J. Terborgh, J. S. Brashares, M. E. Power, J. Berger, W. J. Bond, S. R. Carpenter, T. E. Essington, R. D. Holt, J. B. Jackson \& R. J. Marquis, 2011. Trophic downgrading of planet Earth. Science 333: 301-306.
EU. (2005). Common Implementation Strategy for the Water Framework Directive (2000/60/EC) Guidance document no 13. Overall approach to the classification of ecological status and ecological potential.

Ficetola, G. F. M., E. Siesa, F. De Bernardi \& E. PadoaSchioppa, 2012. Complex impact of an invasive crayfish on freshwater food webs. Biodiversity and Conservation 21: 2641-2651.

Finlay, J. C., 2004. Patterns and controls of lotic stable carbon isotope ratios. Limnology and Oceanography 49: 850-861.

Finlay, J. C., M. E. Power \& G. Cabana, 1999. Effects of water velocity on algal carbon isotope ratios: implications for river food web studies. Limnology and Oceanography 44: 1198-1203.

France, R. L., 1995. Critical examination of stable isotope analysis as a means for tracing carbon pathways in stream ecosystems. Canadian Journal of Fisheries and Aquatic Sciences 52: 651-656.

France, R. L., 1996a. Carbon-13 conundrums: limitations and cautions in the use of stable isotope analysis in stream ecotonal research. Canadian Journal of Fisheries and Aquatic Sciences 53: 1916-1919.

France, R. L., 1996b. Absence or masking of metabolic fractionations of $13 \mathrm{C}$ in a freshwater benthic food web. Freshwater Biology 36: 1-6.

France, R., J. Holmquist, M. Chandler \& A. Cattaneo, 1998. delta super (15) $\mathrm{N}$ evidence for nitrogen fixation associated with macroalgae from a seagrass-mangrove-coral reef system. Marine Ecology Progress Series 167: 297-299.

García, L., W. F. Cross, I. Pardo \& J. S. Richardson, 2017. Effects of landuse intensification on stream basal resources and invertebrate communities. Freshwater Science 36: $609-625$.

Gasith, A. \& V. H. Resh, 1999. Streams in Mediterranean climate regions: abiotic influences and biotic responses to predictable seasonal events. Annual Review of Ecology, Evolution and Systematics 30: 51-81.

González-Pérez, J. A., N. T. Jiménez-Morilloa, J. M. de la Rosa, G. Almendros \& F. J. González-Vila, 2015. Pyrolysis-gas chromatography-isotope ratio mass spectrometryof polyethylene. Journal of Chromatography A 1388: 236-243.

Gray, C., D. J. Baird, S. Baumgartner, U. Jacob, G. B. Jenkins, E. J. O'Gorman, X. Lu, A. Ma, M. J. Pocock, N. Schuwirth, M. Thompson \& G. Woodward, 2014. FORUM: ecological networks: the missing links in biomonitoring science. Journal of Applied Ecology 51: 1444-1449.

Gutierrez-Yurrita, P. J. \& C. Montes, 2001. Bioenergetics of juveniles of red swamp crayfish (Procambarus clarkii). Comparative Biochemistry and Physiology, Part A. Molecular and Integrative Physiology 130: 29-38.

Hamilton, S. K. \& W. M. Lewis, 1992. Stable carbon and nitrogen isotopes in algae and detritus from the Orinoco River floodplain, Venezuela. Geochimica et Cosmochimica Acta 56: 4237-4246.

Hamilton, S. K., J. L. Tank, D. F. Raikow, W. M. Wollheim, B. J. Peterson \& J. R. Webster, 2001. Nitrogen uptake and transformation in a midwestern US stream: a stable isotope enrichment study. Biogeochemistry 54: 297-340.

Ilhéu, M., J. M. Bernardo \& S. Fernandes, 2007. Predation of invasive crayfish on aquatic vertebrates: the effect of 
Procambarus clarkii on fish assemblages in Mediterranean temporary streams. In Gherardi, F. (ed.), Biological Invaders in Inland Waters: Profiles, Distribution, and Threats. Springer, Dordrecht: 543-558.

Ishikawa, N. F., H. Doi \& J. C. Finlay, 2012. Global metaanalysis for controlling factors on carbon stable isotope ratios of lotic periphyton. Oecologia 170: 541-549.

Jackson, A. L., R. Inger, A. C. Parnell \& S. Bearhop, 2011. Comparing isotopic niche widths among and within communities: SIBER-Stable Isotope Bayesian Ellipses in R. Journal of Animal Ecology 80: 595-602.

Jackson, M. C., I. Donohue, A. L. Jackson, J. R. Britton, D. M. Harper \& J. Grey, 2012. Population-level metrics of trophic structure based on stable isotopes and their application to invasion ecology. PLoS ONE. https://doi.org/10. 1371/journal.pone.0031757.

Junker, B. H., 2008. Networks in biology. In Junker, B. H. \& F. Schreiber (eds), Analysis of biological networks. Wiley, Hoboken (NJ): 3-14.

Lauridsen, R. B., F. K. Edwards, W. F. Cross, G. Woodward, A. G. Hildrew \& J. I. Jones, 2014. Consequences of inferring diet from feeding guilds when estimating and interpreting consumer resource stoichiometry. Freshwater Biology 59: 1497-1508.

Layer, K., J. O. Riede, A. G. Hildrew \& G. Woodward, 2010. Food web structure and stability in 20 streams across a wide ph gradient. Advances In Ecological Research, Academic Press 42: 265-299.

Layman, C. A., D. A. Arrington, C. G. Montaña \& D. M. Post, 2007. Can stable isotope ratios provide for communitywide measures of trophic structure? Ecology 88: 42-48.

Layman, C. A., B. D. Araujo, R. Boucek, C. M. HammerschlagPeyer, E. Harrison, Z. R. Jud, P. Matich, A. E. Rosenblatt, J. J. Vaudo, L. A. Yeager \& D. M. Post, 2012. Applying stable isotopes to examine food web structure: an overview of analytical tools. Biological Reviews 87: 545-562.

Ledger, M. E., L. E. Brown, F. K. Edwards, A. M. Milner \& G. Woodward, 2013. Drought alters the structure and functioning of complex food webs. Nature Climate Change 3: 223.

Lewis Jr., W. M., S. K. Hamilton, M. A. Rodriguez, J. F. Saunders III \& M. A. Lasi, 2001. Food web analysis of the Orinoco floodplain based the aquatic food web of a tropical lowland stream based on production estimates and stable isotope data. Journal of the North American Benthological Society 20: 241-254.

López-Rodríguez, M. J., J. M. Luzón-Ortega \& J. M. Tierno de Figueroa, 2012a. On the biology of two high mountain populations of stoneflies (Plecoptera, Perlodidae) in the southern Iberian Peninsula. Limnetica 31: 205-212.

López-Rodríguez, M. J., I. Peralta-Maraver, B. Gaetani, C. E. Sainz-Cantero, R. Fochetti \& J. M. T. de Figueroa, 2012b. Diversity patterns and food web structure in a Mediterranean intermittent stream. International Review of Hydrobiology 97: 485-496.

Macko, S. A., M. L. Fogel, P. E. Hare \& T. C. Hoering, 1987. Isotopic fractionation of nitrogen and carbon in the synthesis of amino acids by microorganisms. Chemical Geology 65: 79-92.
McHugh, P. A., R. M. Thompson, H. S. Greig, H. J. Warburton \& A. R. McIntosh, 2015. Habitat size influences food web structure in drying streams. Ecography 38: 700-712.

McKane, R. B., L. C. Johnson, G. R. Shaver, K. J. Nadelhoffer, E. B. Rastetter, B. Fry, et al., 2002. Resource-based niches provide a basis for plant species diversity and dominance in arctic tundra. Nature 415: 68-71.

McNelly, C., S. M. Clinton \& J. M. Erbe, 2006. Landscape variation in $\mathrm{C}$ sources of scraping primary consumers in streams. Journal of the North American Benthological Society 25: 787-799.

McWilliam-Hughes, S., M. Jardine \& R. A. Cunjak, 2009. Instream $C$ sources for primary consumers in two temperate, oligotrophic rivers: possible evidence of bryophytes as a food source. Journal of the North American Benthological Society 28: 733-743.

Merritt, R. K. \& K. W. Cummins, 1996. An introduction to the aquatic insects of North America, 3rd ed. Dubuque Iowa, Kendall/Hunt Publishers.

Mihuc, T. B., 1997. The functional trophic role of lotic primary consumers: generalist versus specialist strategies. Freshwater Biology 37: 455-462.

Minagawa, M. \& E. Wada, 1984. Stepwise enrichment of $15 \mathrm{~N}$ along food chains: further evidence and the relation between $\mathrm{d} 15 \mathrm{~N}$ and animal age. Geochimica et Cosmochimica Acta 48: 1135-1140.

Mor, J. R., A. Ruhí, E. Tornés, H. Valcárcel, I. Muñoz \& S. Sabater, 2018. Dam regulation and riverine food-web structure in a Mediterranean river. Science of the Total Environment 625: 301-310.

Mulholland, P. J., J. L. Tank, D. M. Sanzone, W. M. Wollheim, B. J. Peterson, J. R. Webster \& J. L. Meyer, 2000. Food resources of stream macroinvertebrates determined by natural-abundance stable $\mathrm{C}$ and $\mathrm{N}$ isotopes and a $15 \mathrm{~N}$ tracer addition. Journal of the North American Benthological Society 19: 145-157.

Nielsen, J. M., E. L. Clare, B. Hayden, M. T. Brett \& P. Kratina, 2018. Diet tracing in ecology: method comparison and selection. Methods in Ecology and Evolution 9: 278-291.

O'Gorman, E. J., J. E. Fitch \& T. P. Crowe, 2012. Multiple anthropogenic stressors and the structural properties of food webs. Ecology 93: 441-448.

Osmond, C. B., N. Valaane, S. M. Haslam, P. Uotila \& Z. Roksandic, 1981. Comparisons of $\delta 13 \mathrm{C}$ values in leaves of aquatic macrophytes from different habitats in Britain and Finland; some implications for photosynthetic processes in aquatic plants. Oecologia 50: 117-124.

Palmer, S. M., D. Hope, M. F. Billett, J. J. Dawson \& C. L. Bryant, 2001. Sources of organic and inorganic carbon in a headwater stream: evidence from carbon isotope studies. Biogeochemistry 52: 321-338.

Parnell, A. \& A. Jackson, 2013. siar: Stable Isotope Analysis in R. R package version 4.2. https://CRAN.R-project.org/ package $=$ siar.

Pascual, M. \& J. A. Dunne (eds), 2006. Ecological Networks: Linking Structure to Dynamics in Food Webs. Oxford University Press, Oxford.

Pearson, T. H. \& R. Rosenberg, 1978. Macrobenthic succession in relation to organic enrichment and pollution of the marine environment. Oceanography and Marine Biology 16: $229-311$. 
Peipoch, M., E. Martí \& E. Gacia, 2012. Variability in $\delta 15 \mathrm{~N}$ natural abundance of basal resources in fluvial ecosystems: a meta-analysis. Freshwater Science 31: 1003-1015.

Peterson, B. J. \& B. Fry, 1987. Stable isotopes in ecosystem studies. Annual review of ecology and systematics 18: 293-320.

Pusey, B. J., A. H. Arthington, B. Stewart-Koster, M. J. Kennard \& M. G. Read, 2010. Widespread omnivory and low temporal and spatial variation in the diet of fishes in a hydrologically variable northern Australian river. Journal of Fish Biology 77: 731-753.

R Core Team, 2012. R: A language and environment for statistical computing. R Foundation for Statistical Computing, Vienna, Austria URL http://www.R-project.org/.

Rezanka, K. M. \& A. E. Hershey, 2003. Examining primary producer-consumer interactions in a Lake Superior tributary using $15 \mathrm{~N}$-tracer, grazer-reduction, and nutrientbioassay experiments. Journal of the North American Benthological Society 22: 371-387.

Rosenfeld, J. S. \& J. C. Roff, 1992. Examination of the carbon base in southern Ontario streams using stable isotopes. Journal of the North American Benthological Society 11: $1-10$.

Sabater, S., H. Guasch, A. M. Romaní, I. Muñoz \& S. S. Cortés, 2006. Hydrology, light and the use of organic and inorganic materials as structuring factors of biological communities in Mediterranean streams. Limnetica 25: 335-348.

Sabo, J. L., J. C. Finlay, T. Kennedy \& D. M. Post, 2010. The role of discharge variation in scaling of drainage area and food chain length in rivers. Science 330: 965-967.

Sackett, W. M., W. R. Eckelmann, M. L. Bender \& A. W. Bé, 1965. Temperature dependence of carbon isotope composition in marine plankton and sediments. Science (Washington, DC) 148: 235-237.

Sánchez-Carmona, R., L. Encina, A. Rodríguez-Ruiz, M. V. Rodríguez-Sánchez \& C. Granado-Lorencio, 2012. Food web structure in Mediterranean streams: exploring stabilizing forces in these ecosystems. Aquatic Ecology 46: 311-324.

Schmidt, S. N., C. J. Harvey \& M. J. Vander Zanden, 2011. Historical and contemporary trophic niche partitioning among Laurentian Great Lakes coregonines. Ecological Applications 3: 888-896.

SNIRH, Sistema Nacional de Informação de Recursos Hídricos - http://www.snirhpt/. Accessed 05 December 2016.

Sroczyńska, K., M. Claro, A. Kruk, A. Wojtal-Frankiewicz, P. Range \& L. Chícharo, 2017. Indicator macroinvertebrate species in a temporary Mediterranean river: Recognition of patterns in binary assemblage data with a Kohonen artificial neural network. Ecological Indicators 73: 319-330.

Stewart, K.W. \& B.P. Stark,1988. Nymphs of North American stonefly genera (Plecoptera). Entomological Society of America.
Stubbington, R., J. England, P. J. Wood \& C. E. M. Sefton, 2017. Temporary streams in temperate zones: recognizing, monitoring and restoring transitional aquatic-terrestrial ecosystems. WIREs Water 4: e1223.

Tachet, H., M. Bournaud, P. Richoux \& P. Usseglio-Polatera, 2002. Invertébrés d'eau douce: systématique, biologie, écologie. CNRS Editions, Paris: 588.

Tank, J. L., J. L. Meyer, D. M. Sanzone, P. J. Mulholland, J. R. Webster, B. J. Peterson \& N. E. Leonard, 2000. Analysis of nitrogen cycling in a forest stream during autumn using a $15 \mathrm{~N}$-tracer addition. Limnology and Oceanography 45: 1013-1029.

Thompson, R. M., U. Brose, J. A. Dunne, R. O. Hall, S. Hladyz, R. L. Kitching \& J. M. Tylianakis, 2012. Food webs: reconciling the structure and function of biodiversity. Trends in Ecology and Evolution 27: 689-697.

Tylianakis, J. M., T. Tscharntke \& O. T. Lewis, 2007. Habitat modification alters the structure of tropical host-parasitoid food webs. Nature 445: 202.

Vanderklift, M. A. \& S. Ponsard, 2003. Sources of variation in consumer-diet $\delta 15 \mathrm{~N}$ enrichment: a metaanalysis. Oecologia 136: 169-182.

Vannucchi, P. E., M.J. López-Rodríguez, J.M. Tierno de Figueroa \& E. Gaino, 2013. Structure and dynamics of a benthic trophic web in a Mediterranean Seasonal Stream. https://doi.org/10.4081/jlimnol.2013.e51

Vannucchi, P. E., I. Peralta-Maraver, J. M. Tierno de Figueroa \& M. J. López-Rodríguez, 2017. Dynamics of the macroinvertebrate community and food web of a Mediterranean stream. Journal of Freshwater Ecology 32: 229-245.

Villéger, S., N. W. H. Mason \& D. Mouillot, 2008. New multidimensional functional diversity indices for a multifaceted framework in functional ecology. Ecology 89: 2290-2301.

Wienke, C. \& G. Fisher, 1990. Growth and stable carbon isotope composition of cold-water macroalgae in relation to light and temperature. Marine Ecology Progress Series 65: 283-292.

Williams, D. D., 2006. The Biology of Temporary Waters. Oxford University Press, Oxford.

Winterbourn, M. J., J. S. Rounick \& A. G. Hildrew, 1986. Patterns of carbon resource utilization by benthic invertebrates in two river systems: a stable carbon isotope study. Archive fur Hydrobiologie 107: 349-361.

Zanden, M. \& J. B. Rasmussen, 2001. Variation in $\delta 15 \mathrm{~N}$ and $\delta 13 \mathrm{C}$ trophic fractionation: implications for aquatic food web studies. Limnology and Oceanography 46: 2061-2066.

Publisher's Note Springer Nature remains neutral with regard to jurisdictional claims in published maps and institutional affiliations. 